Erschienen in: Science ; 366 (2019), 6466. - S. 698-699

https://dx.doi.org/10.1126/science.aaz9045

\title{
Climate concerns and the disabled community
}

Climate change and the loss of ecosystem services are likely to disproportionately affect the world's disabled populations by 
accentuating inequalities and increasing marginalization of the most vulnerable members of society $(1,2)$. Disabled populations may experience a limited access to knowledge, resources, and services to effectively respond to environmental change (3). Compromised health may make people more vulnerable to extreme climate events, ecosystem services loss, or infectious disease exposure (4), and those with disabilities are more likely to have difficulties during required evacuations or migrations $(5,6)$. For example, Hurricane Katrina was found to disproportionately impact 155,000 people with disabilities ranging from visual and physical impairments to learning disabilities (7). The international research community has made good progress at including vulnerable groups such as poor communities, women, indigenous people, and youth in recent international conversations about global environmental change $(8,9)$, but disabled populations have been mostly absent from the conversation.

In a positive step this past July, the United Nations Human Rights Council adopted a resolution calling on governments to adopt a disability-inclusive approach to addressing climate change $(10,11)$. However, more needs to be done at the international level. Two leading international bodies assessing the knowledge and impacts of climate change and the loss of ecosystem services-the Intergovernmental Panel on Climate Change (IPCC) and the Intergovernmental Science-Policy Platform on Biodiversity and Ecosystem Services (IPBES)-have, thus far, done little to address the critical implications of climate change and biodiversity loss for disabled populations $(8,12)$. Global environmental change should be considered a disability rights issue. The formation of dedicated task forces within IPCC and IPBES will be critical for increasing research and including persons with disabilities in the conversation around climate resilience to better tackle this pressing global challenge.

Aleksandra Kosanic ${ }^{1 *}$, Jan Petzold², Amy Dunham³, Mialy Razanajatovo ${ }^{1}$

1Department of Biology, Ecology, University of Konstanz, Konstanz, Baden-Württemberg, 78457, Germany. ${ }^{2}$ Center for Earth System Research and Sustainability (CEN), Universität Hamburg, 20146 Hamburg, Germany. ${ }^{3}$ Department of BioSciences, Rice University, Houston, TX 77251, USA.

*Corresponding author.

Email: sasa.kosanic@gmail.com

\section{REFERENCE AND NOTES}

1. D. Attenborough, Nature 573,463 (2019)

C. Bellard, C. Bertelsmeier, P. Leadley, W. Thuiller, F. Courchamp, Ecol. Lett. 15, 365 (2012).

3. L. Hemingway, M. Priestley, Rev. Disabil. Stud. Intl. J. 2 $1(2006)$.

4. N. Watts et al., Lancet 392, 2479 (2018)

5. J. Twigg, E. Cole, M. Kett, M. Simard, F. Smith, Disability and Climate Resilience. A Literature Review (University College London, 2017).

6. D. M. Perry, "Disability and disaster response in the age of climate change," Pacific Standard (2017); https://psmag.com/environment/ fixing-americas-disability-disaster-response.

7. G. Wolbring,Aculture of neglect: Climate discourse and disabled people. M/C J. 12,1 (2009).

8. IPCC, "Summary for Policymakers," in Global Warming of $1.5^{\circ} \mathrm{C}$ : An IPCC Special Report on the Impacts of Global Warming of $1.5^{\circ} \mathrm{C}$ Above Pre-Industrial Levels and Related Global Greenhouse Gas Emission Pathways, in the Context of Strengthening the Global Response to the Threat of Climate Change, Sustainable Development, and Efforts to Eradicate Poverty, V. Masson-Delmotte et al., Eds. (2018)

9. J. D. Ford et al., Nat. Clim. Change 6, 349 (2016).

10. United Nations, "General Assembly Resolution hrc41, Climate Change and Disability A/HRC/41/L.24." (United Nations, New York, 2019)

11. United Nations, "Disability and development reportRealizing the Sustainable Development Goals by, for and with persons with disabilities" (United Nations. New York, 2019).

12. H. T. Ngo et al.," "The draft Chapter 1 of the IPBES Global Assessment on Biodiversity and Ecosystem Services" (IPBES, 2019). 